\title{
Foot Bone Marrow Edema after a 10-wk Transition to Minimalist Running Shoes
}

\author{
Sarah T. Ridge \\ Brigham Young University, sarah_ridge@byu.edu
}

A. Wayne Johnson

Brigham Young University - Provo, wayne_johnson@byu.edu

Ulrike H. Mitchell

Brigham Young University - Provo, rike_mitchell@byu.edu

lain Hunter

Brigham Young University, iain_hunter@byu.edu

Eric Robinson

Follow this and additional works at: https://scholarsarchive.byu.edu/facpub

Part of the Exercise Science Commons

See next page for additional authors

\section{Original Publication Citation}

Ridge, S, Johnson, A, Mitchell, U, Hunter, I, Robinson, E, Rich, B, Brown, SD. (2013). Foot bone marrow edema after 10 week transition to minimalist running shoes. Medicine and Science in Sports and Exercise, 45(7), 1363-1368.

\section{BYU ScholarsArchive Citation}

Ridge, Sarah T.; Johnson, A. Wayne; Mitchell, Ulrike H.; Hunter, lain; Robinson, Eric; Rich, Brent S. E.; and Brown, Stephen Douglas, "Foot Bone Marrow Edema after a 10-wk Transition to Minimalist Running Shoes" (2013). Faculty Publications. 2014.

https://scholarsarchive.byu.edu/facpub/2014

This Peer-Reviewed Article is brought to you for free and open access by BYU ScholarsArchive. It has been accepted for inclusion in Faculty Publications by an authorized administrator of BYU ScholarsArchive. For more information, please contact ellen_amatangelo@byu.edu. 


\section{Authors}

Sarah T. Ridge, A. Wayne Johnson, Ulrike H. Mitchell, lain Hunter, Eric Robinson, Brent S. E. Rich, and Stephen Douglas Brown 


\title{
Foot Bone Marrow Edema after a 10-wk Transition to Minimalist Running Shoes
}

Ridge, Sarah T.; Johnson, A. Wayne; Mitchell, Ulrike H.; Hunter, Iain; Robinson, Eric; Rich, Brent S. E.; Brown, Stephen Douglas

\begin{abstract}
Purpose: Minimalist running shoes are becoming a more popular choice for runners in the past few years. However, there is little conclusive evidence about the advantages or disadvantages of running in these shoes. Although performance benefits may exist, injury may also occur from the added stress of running without the benefit of cushioning under the foot. Bone marrow edema can be a manifestation of added stress on the foot. This study measured bone marrow edema in runners' feet before and after a 10-wk period of transitioning from traditional to minimalist running shoes.
\end{abstract}

Methods: Thirty-six experienced recreational runners underwent magnetic resonance imaging (MRI) before and after a 10-wk period. Seventeen subjects were in the control group (ran in their traditional shoes only for $10 \mathrm{wk}$ ), whereas the other 19 were in the experimental group (gradually transitioned to Vibram FiveFinger running shoes for $10 \mathrm{wk}$ ). The severity of the bone marrow edema was scored on a range of $0-4(0=$ no bone marrow edema, $4=$ edema in more than $50 \%$ of the length of the bone). A score of 4 represented a stress fracture.

Results: Pretraining MRI scores were not statistically different between the groups. The posttraining MRI scores showed that more subjects in the Vibram group (10 of 19) showed increases in bone marrow edema in at least one bone after $10 \mathrm{wk}$ of running than that in the control group $(P=0.009)$.

Conclusion: Runners interested in transitioning to minimalist running shoes, such as Vibram FiveFingers, should transition very slowly and gradually to avoid potential stress injury in the foot.

Keywords: stress injury, runners, footwear, MRI

\section{INTRODUCTION}

Before the 1970s, before the development of the modern, traditional running shoe, individuals ran either barefooted or in minimal footwear, such as modified sandals $(\underline{13,17})$. Recently, it has been suggested that running in traditional running shoes, which usually have a cushioned sole, may result in reduced performance (23), increased risk of injury (르), limitation of proprioception ( $\underline{13})$, and increased ground collision forces in rear-foot strikers ( $\underline{13})$. For these 
reasons, there has been a recent resurgence in the running community of running barefoot and/or in minimalist shoes (4). Consequently, shoe manufacturers are continually releasing new models of minimalist shoes to accommodate this growing interest. Concurrently, research is being conducted to assess potential benefits of running in minimalist shoes. Research examining barefoot running has reported that habitual barefoot endurance runners experience fewer running-related injuries than shod runners, although the conditions within the Haitian population measured may influence those results (18). The American Podiatric Medical Association position statement on barefoot running states that it "has been touted as improving strength and balance, while promoting a more natural running style. However, risks of barefoot running include a lack of protection — which may lead to injuries such as puncture wounds and increased stress on the lower extremities. Currently, inconclusive scientific research has been conducted regarding the benefits and/or risks of barefoot running” (1). Minimalist running shoes are designed to allow runners to use the same mechanics as in barefoot running without the risk of injury due to contact between the bare foot and the ground. Because of the increasing popularity of minimalist running shoes, it is imperative that researchers, clinicians, and runners understand the potential risks present when transitioning from running in traditional running shoes to minimalist running shoes.

One of the primary concerns of barefoot/minimalist running is that although foot musculature may be strengthened, injury may result from the added stress placed on the bones in the foot, especially throughout the adaptation period when runners transition from traditional running shoes (ㅁ). This is of particular concern, considering the incidence of stress syndrome or fractures in runners, even in traditional shoes (14). Similarly, runners may be at risk for developing tendinitis and plantar fasciitis during this critical time frame. It has been suggested that most runners will transition from a rear-foot strike to a mid- or forefoot strike when running barefoot or in minimalist running shoes $(\underline{5,7,13,20})$. The lack of cushioning under the foot during this transition may place the runner at greater risk for stress injury at the mid- or forefoot. If a runner does not adapt from a rear-foot strike pattern, the large forces (1.5-3 times body weight) associated with foot strike during running will be transmitted directly to the heel, without the assistance of the shock-absorbing sole of the running shoe (13). This increases the potential for injury to the bony and soft tissue structures of the heel and lower extremity. Anecdotally, clinicians have reported an increase in foot injuries in runners while transitioning to minimalist shoes. Although there is a lack of conclusive evidence in scientific literature, Giuliani et al. (ㅁ) report two cases of stress fractures in runners as they transitioned to minimalist running shoes.

A very sensitive measurement tool must be used to determine risk of stress injury in the foot due to transitioning to minimalist running shoes. Although some overuse injuries, such as stress fractures and callus, can be seen on X-rays, a more sensitive measurement tool is necessary to

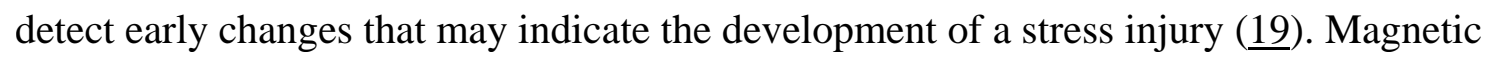
resonance imaging (MRI) makes it possible to detect bone stress injuries of the ankle and foot 
weeks before radiographs would demonstrate osseous abnormalities $(\underline{6,11,19})$. Early changes of stress injury to bone are characterized by reabsorption and replacement of bone, marked by local hyperemia and edema, which may be missed in early radiographic imaging but can be captured by MRI $(\underline{6,16,19})$. An additional advantage of MRI is the ability to grade and classify lesions (11). Grading is performed by assessing the presence of endosteal marrow edema, periosteal edema, muscle edema, and existence of a fracture line and callus formation. Niva et al. ( $\underline{16})$ found that early detection and grading of bone stress injuries was not only possible using MRI but also essential in early and appropriate injury management. It has been suggested that MRI should be used as the gold standard in the assessment of stress injuries of bone (11). A previous study showed that bone marrow edema changes in the foot were detectable with MRI after just 1 wk of running (21).

There has been evidence of MRI detecting stress reactions in athletes and military recruits who are asymptomatic $(\underline{3,10})$. These asymptomatic stress reactions were low-grade bone response ( $<3$ on a 0 - to 4 -point scale), and a score of 4 (stress fracture) was associated with symptoms $(\underline{3,10})$. Despite this, MRI is still the one of the best objective tools available to measure the reaction of bones and tendons to stress.

The purpose of this study was to assess bone and soft tissue changes in experienced, recreational runners during a 10-wk transitional period from traditional to minimalist running shoes. We hypothesized that the prevalence of bone and soft tissue changes would be greater in the runners who transitioned to minimalist shoes compared with those runners who continued running in traditional running shoes throughout the same period.

\section{METHODS}

Thirty-six experienced recreational runners (21 men and 15 women) participated in this study (age $=26.5 \pm 6.6 \mathrm{yr}$, height $=175.2 \pm 10.1 \mathrm{~cm}$, mass $=70.5 \pm 11.8 \mathrm{~kg}$; mean $\pm \mathrm{SD})$. To qualify for participation, runners had to complete an average of $15-30$ miles $^{*} \mathrm{wk}^{-1}$ for the 6 months before the start of the study. Subjects were excluded if they had ever run in Vibrams before the study or if they had experienced a lower body injury that kept them from running at least 3 $\mathrm{d} \cdot \mathrm{wk}^{-1}$ at any time in the previous 6 months. All subjects signed institutionally approved informed consent forms and completed a medical/injury history questionnaire documenting that they were pain free before participation in the study. Subjects were also screened by a physician and received a preparticipation MRI of the foot, ensuring that there were no preexisting injuries. Forty-three subjects began this study. Subjects were randomly assigned to the minimalist (Vibram) or control group. To avoid the chances of a large discrepancy between the number of men and women in either group, the male subjects drew group assignments out of one bag, and the females subjects drew out of another bag. In each bag were equal numbers of Vibram and control assignments. Seven subjects did not complete the study for a variety of reasons-three 
subjects completed the training but did not return for a follow-up MRI; two subjects were injured during the course of the $10 \mathrm{wk}$, unrelated to participation in this study; and another two subjects did not respond to contact after their initial MRI.

Both groups were encouraged to continue their typical running regimen throughout the 10 -wk period after the initial MRI. The Vibram group transitioned from traditional running shoes to Vibram FiveFinger ${ }^{\mathrm{TM}}$ (VFF) running shoes gradually during that time by replacing some mileage in traditional shoes each week with mileage in the VFF. The transition protocol used in this study was modeled from suggestions for transitioning to VFF published on the VFF Web site in January 2011 (the suggestions on the Web site have changed since then) (22).

Participants in the Vibram group were instructed to run one short (1-2 mile) run in the VFF during their first week of training. During the next 2 wk, they were to run in the VFF for one additional short (1-2 mile) run each week; thus, during week 3, they would run at least 3 miles in the VFF. After the third week of running, subjects were advised to add mileage in the VFF as they felt comfortable, with the goal of replacing one short run per week in traditional shoes with a short run in the VFF. The flexibility of this protocol was chosen to allow the subjects to transition as they would if they had just bought the shoes and were not participating in a research study. Although the lack of control over how much each subject ran in the Vibrams each day is a limitation to scientific research, this more accurately simulated a real-life situation. To understand how each subject transitioned, all subjects kept a training log to document the length of each run, the time spent running, the footwear worn, and any foot/leg pain. After 10 wk of running, all subjects reported back for a follow-up MRI. MRI scans were taken in the morning, and subjects were instructed not to run that day before their appointment.

MR images were taken using a Hitachi 0.7-T Altaire “open” magnet (Hitachi Medical Systems America, Inc., Twinsburg, $\mathrm{OH}$ ). Both feet were placed in a head coil and then placed in an isocenter position within the magnet. The field of view included the entire foot, including the distal tibia and fibula. Axial (long-axis) and sagittal T2-weighted fast short tau inversion recovery (FIR) images and axial T1-weighted spin echo images were obtained. Axial T1weighted images were performed with a 23-cm field of view, $256 \times 192$ matrix, 5-mm thickness and 2-mm spacing, $455 \mathrm{~ms}$ repetition time (TR), and $18 \mathrm{~ms}$ echo time (TE). Axial FIR images were performed with a 23-cm field of view, $256 \times 176$ matrix, 5-mm thickness with 2-mm spacing, $3000 \mathrm{~ms}$ TR, $14 \mathrm{~ms}$ TE, and 110 inversion time. Sagittal FIR images were performed with a 23-cm field of view, $256 \times 176$ matrix, 5-mm thickness and 1-mm spacing, $3690 \mathrm{~ms}$ TR, $12 \mathrm{~ms}$ TE, and $110 \mathrm{~ms}$ inversion time. 
Bone marrow edema was scored according to a system based on the method used by Lazzarini et al. (12), as described in Table 1A. The Achilles tendon, dorsiflexor, plantarflexor, peroneal tendons, and plantar fascia were scored with the scoring system shown in Table 1B. Images were independently reviewed using a Dominator DR PACS workstation by three trained and board-certified musculoskeletal radiologists. The radiologists were blinded to control and minimalist runners. Radiologists compared the before and after images of the 10-wk training. Consensus was considered achieved when two of the three radiologists were in agreement with both the pre- and the postscores. If all three radiologists reported different scores, they were shown the images again and asked to rescore them. They were blinded to the other radiologists' scores. In all cases, the rescoring resulted in consensus between the radiologists the first time they reanalyzed the images. To quantify the intrarater reliability of the radiologists, each doctor rescored 20 images. The initial scores of the 20 images ranged from 0 to 4 . The average intraclass correlation coefficient for the doctors was $0.93 \pm 0.02$.

Data were analyzed using Fisher's exact test in SAS (SAS Institute, Inc, Cary, NC). Subjects were grouped by the severity of posttest MRI findings across all the structures in the foot. Comparisons were made between subjects who had scores of 0 or 1 and those who had at least one structure (on either foot) that showed a score of 2, 3, or 4 in their posttest images. Data were then compared for subjects in the minimalist group with subjects in the control group. Pretest data were also compared to ensure that there were no differences before the start of the study.

\section{RESULTS}

The pretraining MRI scores were not statistically different for the two groups ( $P=1.00$ for bone, $P=0.191$ for soft tissue). The posttraining MRI scores showed that more subjects in the Vibram group showed increases in bone marrow edema in at least one bone after the 10 wk of running than that in the control group (see Table 2; $P=0.009$ ). The groups were not significantly different with respect to posttraining MRI scores in the soft tissue $(P=0.444)$. Only one subject had a posttest tendon score of 2 in the plantar fascia. The pretest tendon score for that subject's plantar fascia was also 2. No subjects had a tendon score of 3 during pre- or posttest measurements.

Table 3 shows the magnitude of the marrow edema scores (MES) during the posttraining MRI for the most commonly reported locations of bone injury in the foot $(\underline{12,15,24})$. These numbers represent the total number of structures showing bone marrow edema changes in all feet. These results show a higher incidence of intense signal subfracture bone marrow edema as designated by an MES of 3 (stress injury) in the Vibram group (3 of 19 subjects in the Vibram group compared with 0 of 17 
subjects in the control group). However, a particular individual may have had more than one involved bone. For example, one individual had bilateral increased signal to an MES of 3 in the second metatarsal and unilateral increased signal in the third metatarsal. Another subject showed bilateral increased signal in the talus, whereas another individual only had increased signal in one of their third metatarsals. Increased signal intensity in the feet of the Vibram group to an MES of 2 was found in 8 of the 19 participants. Including the two subjects who experienced stress fractures, 10 of the 19 subjects in the Vibram group were classified as “injured” (at least one structure with an MES >=2) at the end of the study.

\section{DISCUSSION}

The results of this study showed that increases in bone marrow edema are more common in subjects who were transitioning to the VFF. Bone marrow edema changes are indicative of added stress and have been seen in sedentary subjects who ran for only $7 \mathrm{~d}$ in a row in traditional running shoes (21). In the current study, few subjects in the control group showed any change (posttest MES =1) in bone marrow edema during the $10 \mathrm{wk}$ of participation in this study, and only one had a posttest MES of 2. This, combined with the findings of Trappeniers et al. (21), suggests that our subjects were conditioned enough through their previous running experience that it was not the running but the added stress of transitioning to VFF that contributed to the higher incidence of bone marrow edema in the Vibram group.

It is important to note that for data analysis, subjects with an MES of 0 or 1 were grouped together because a score of 1 does not necessarily constitute an injury. An MES of 1 could very well be the product of the physiologic phenomenon of osseous remodeling due to stress, which is essential to the normal development and maintenance of bone (2). With the appropriate application of stress, the remodeling process results in a stronger bone structure-which is visible on the MRI by low levels of bone marrow edema. However, if continued stress occurs more frequently than the remodeling, this can result in an imbalance that renders cortical and trabecular bone weakened (19). Persistent stress could further lead to bone fatigue, injury, or fracture, represented by increasing amounts of bone marrow edema, respectively. Edema in $25 \%-50 \%$ of the bone (MES = 2) is considered a stress reaction and a potential cause for concern. At this point, running should be limited and cross training should be encouraged. Edema in more than $50 \%$ of the bone length (MES = 3) is considered a stress injury, at which point participation in running should cease. Of the 19 Vibram group participants, 9 had edema grades of 0 and 1 (noninjured) and 10 had edema grades of 2, 3, or 4 (injured). This is significantly higher compared with the control group, where 16 subjects were considered noninjured and only 1 subject was considered injured. Although most runners will not know 
about the presence or degree of bone marrow edema, our results suggest that if a runner transitioning to VFF feels pain, they should modify their running regimen.

The location of the fractures and bone marrow edema observed in our study are comparable with other studies $(\underline{12,15,24})$. Of the 19 participants, 2 in the Vibram group experienced stress fractures as indicated by an MES score of 4, whereas the shod running group showed no fractures. One individual in the Vibram group experienced a calcaneal fracture, and another had a second metatarsal fracture. Tarsal and metatarsal stress fractures have been reported by other researchers investigating athletes and military recruits $(\underline{12,24})$. In a study of 320 athletes with stress fractures, researchers found that tarsal fractures (25.3\%) were the second most commonly fractured bones after the tibia (49.1\%), and metatarsal fractures (8.8\%) were the third most common (15). In a review of studies investigating stress fracture incidence, the occurrence of stress fractures in athletes ranged from $1.4 \%$ to $18.3 \%$ in tarsal bones, and stress fractures in the metatarsals ranged from $8 \%$ to $24.6 \%$ (24). Some studies only reported stress fractures in the foot, which ranged from $28 \%$ to $33.8 \%(\underline{24})$. The tibia appears to be the most likely of the lower extremity bones to experience stress fractures in an athletic population, often accounting for $40 \%-50 \%$ of stress fractures (24). None of the participants in our study showed bone marrow edema in the distal tibia during the $10 \mathrm{wk}$ of training. Jones et al. ()ㅡ) stated that in athletic populations, the incidence of stress fractures vary depending on the sports, although the highest generally occurs in female runners. Of the 11 runners who had MES scores of 2 or greater in this study, 8 were women. This may suggest that female runners need to focus on a slower transition to VFF running shoes even more than male runners.

Participants in this study were required to keep a training log to document their running. Although the original intention of the study design was for all subjects to have completely transitioned to VFF running shoes by the end of the $10 \mathrm{wk}$ of training, this did not happen for the majority of subjects. Mileage data from the final week of each subject's training log indicate that only one subject ran exclusively in the VFF during the last week of entries into the training log. It should be noted that some subjects stopped logging their runs before the 10th week of training and 4 of the 19 Vibram subjects did not document their training at all, although they did participate in both pre- and posttesting and therefore were included in the statistical analysis in this study. This lack of documentation presents a limitation to this study.

The subject who was running exclusively in the VFF ran 16-17 miles during the last 2 wk of the study. During the last week, she reported some pain and did change back to traditional shoes for 3 miles of one run. Her only nonzero MES scores were in the left talus (MES =1) and the right talus (MES = 2). 
The data reported from the training logs support the statement that the rate of transition is an important aspect to consider when runners start wearing VFF running shoes. Figure 1 shows mileage data from the control and Vibram subgroups (injured and noninjured) for 1 wk of the study. The week chosen was the week during which the subject ran the most miles in their respective shoe. It should be emphasized that for the Vibram subgroups, these data were not from the week during which the subject ran their total peak mileage (traditional plus VFF mileage) but rather from maximum mileage in the VFF only.

Within the Vibram subgroups, subjects ran their maximum weekly mileage in VFF during a range of weeks (weeks 1-9). Seven subjects ran their maximum mileage in VFF before or during week 4 . This early peak shows that subjects chose not to increase their weekly mileage during the second half of the 10-wk study-possibly due to discomfort, injury, or other difficulty running in the VFF.

Although we do not know why many runners ran their maximum mileage early in the study, perhaps perceived pain is a possible explanation. The perceived pain scale scores recorded on the training logs were highly variable between runners. For example, the two individuals that experienced stress fractures reported perceived pain scores of 2 and 4 of 10 during running, whereas some other runners without injury reported higher pain levels. Again, it should be noted that studies have shown that MRI findings can be positive for stress reactions in asymptomatic individuals $(\underline{3,10})$. Therefore, it is possible that a runner that is transitioning to minimalist running shoes may have a stress reaction but be asymptomatic. Runners who had the highest level of stress injury consistently reported symptoms $(\underline{10})$, supporting the notion that if a runner is feeling consistent pain affecting their ability to run, a modification should be made to their training protocol.

It is also valuable to note that although the Vibram subgroups ran the same mileage in the VFF during the peak week, the noninjured group ran fewer miles in traditional running shoes during that week. This suggests that it may not be only VFF mileage that contributes to injury as much as the total stress on the foot with the added stress of running in the VFF.

\section{CONCLUSION}

Although many runners are making the change to Vibram running shoes, there is currently a lack of agreement on the advantages or disadvantages of this change. This study examined the potential for stress injury by measuring the presence of bone marrow edema and soft tissue damage in the foot after runners transitioned to VFF shoes throughout a 10-wk transition period. The Vibram group had a significantly greater incidence of bone marrow edema after the training period, although neither group showed any soft tissue changes. Thus, to minimize the risk of 
bone stress injury, runners who want to run in VFF should transition for a longer duration than $10 \mathrm{wk}$ and at a lower intensity (miles $\cdot \mathrm{wk}^{-1}$ ) than the subjects in this study.

No external funding was received for this project.

The authors report no conflict of interest.

\begin{tabular}{lll}
\hline (A) & & \\
\hline MES & MRI Finding/Appearance & \multicolumn{1}{c}{ Interpretation } \\
\hline 0 & No edema & Normal \\
1 & Increased T2 signal in & Remodeling \\
& $<25 \%$ of the bone & \\
2 & Increased T2 signal in & Stress reaction-some cause \\
& $25 \%-50 \%$ of the bone & for concern \\
3 & Increased T2 signal in & Stress injury-definite cause \\
& $>50 \%$ of the bone & for concern \\
4 & Fracture line & Fracture \\
\hline
\end{tabular}

(B)

\begin{tabular}{lc}
\hline Tendon Score & MRI Finding/Appearance \\
\hline 0 & Normal \\
1 & Abnormal intrasubstance signal or tenosynovitis \\
2 & Partial tear \\
3 & Full thickness tear \\
\hline
\end{tabular}

(A) Bone marrow edema scores (MES) and corresponding interpretation. (B) Soft tissue (tendon) scores and interpretation.

Table 1 Interval scale used by the radiologists to grade the MR images.

\begin{tabular}{lcc}
\hline Posttest Marrow Edema Score & Control & Vibram \\
\hline Noninjury (0-1) & 16 & 9 \\
Injury (2-4) & 1 & 10 \\
\hline
\end{tabular}

Table 2 Number of subjects in the injury versus noninjury groups. 


\begin{tabular}{lccccc}
\hline & & \multicolumn{4}{c}{ No. Involved Bones/No. Involved Subjects } \\
\hline \multirow{2}{*}{ Second metatarsal } & Motal & $9 \mathrm{~b} / 7 \mathrm{~s}$ & $4 \mathrm{~b} / 3 \mathrm{~s}$ & $2 \mathrm{~b} / 1 \mathrm{~s}$ & $1 \mathrm{~b} / 1 \mathrm{~s}$ \\
& Vibram & $6 \mathrm{~b} / 5 \mathrm{~s}$ & $4 \mathrm{~b} / 3 \mathrm{~s}$ & $2 \mathrm{~b} / 1 \mathrm{~s}$ & $1 \mathrm{~b} / 1 \mathrm{~s}$ \\
\multirow{2}{*}{ Third metatarsal } & Total & $4 \mathrm{~b} / 3 \mathrm{~s}$ & $1 \mathrm{~b} / 1 \mathrm{~s}$ & $2 \mathrm{~b} / 2 \mathrm{~s}$ & 0 \\
& Vibram & $3 \mathrm{~b} / 2 \mathrm{~s}$ & $1 \mathrm{~b} / 1 \mathrm{~s}$ & $2 \mathrm{~b} / 2 \mathrm{~s}$ & 0 \\
Talus & Total & $13 \mathrm{~b} / 10 \mathrm{~s}$ & $5 \mathrm{~b} / 3 \mathrm{~s}$ & $2 \mathrm{~b} / 1 \mathrm{~s}$ & 0 \\
& Vibram & $9 \mathrm{~b} / 5 \mathrm{~s}$ & $5 \mathrm{~b} / 3 \mathrm{~s}$ & $2 \mathrm{~b} / 1 \mathrm{~s}$ & 0 \\
Calcaneus & Total & $10 \mathrm{~b} / 6 \mathrm{~s}$ & $2 \mathrm{~b} / 1 \mathrm{~s}$ & 0 & $1 \mathrm{~b} / 1 \mathrm{~s}$ \\
& Vibram & $9 \mathrm{~b} / 5 \mathrm{~s}$ & $2 \mathrm{~b} / 1 \mathrm{~s}$ & 0 & $1 \mathrm{~b} / 1 \mathrm{~s}$ \\
Navicular & Total & $7 \mathrm{~b} / 6 \mathrm{~s}$ & $1 \mathrm{~b} / 1 \mathrm{~s}$ & 0 & 0 \\
& Vibram & $4 \mathrm{~b} / 3 \mathrm{~s}$ & 0 & 0 & 0 \\
\hline
\end{tabular}

These numbers reflect the total number of bones that showed changes; therefore, some may be the right and left bone from the same subject. Each column reflects the total number of bones/total number of subjects.

Table 3 Number of bones with marrow edema scores greater than or equal to 1 during the posttest MRI for commonly injured bones in runners.

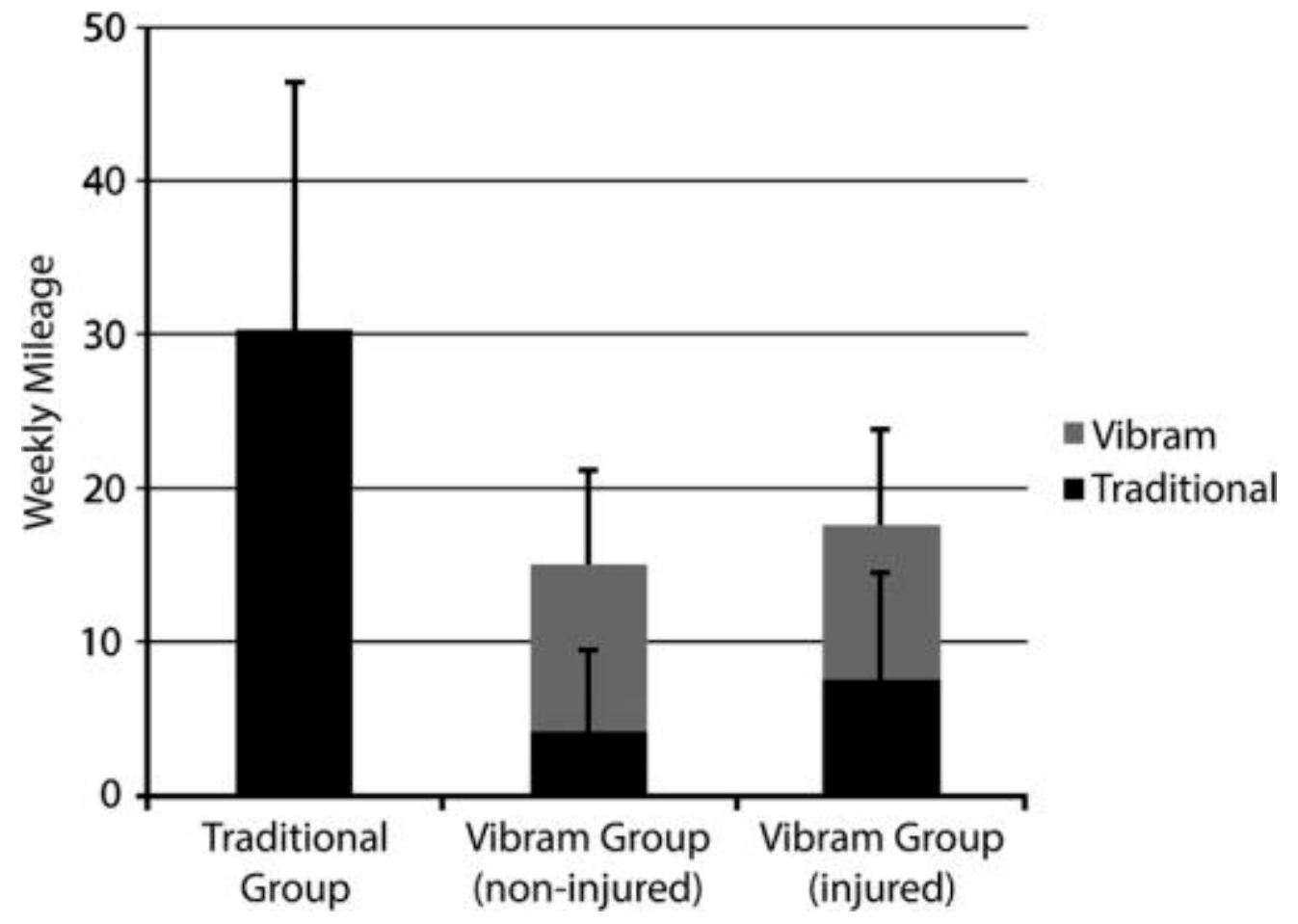

Figure 1. Number of miles (mean \pm SD) subjects ran during their “peak week” of running. 


\section{REFERENCES}

1. American Podiatric Medical Association Web site [Internet]. Bethesda(MD): American

Podiatric Medical Association; [cited 2012 Jan 19]. Available from:

http://www.apma.org.

2. Anderson MW, Greenspan A. Stress fractures. Radiology 1996;199(1):1-12.

3. Bergman AG, Fredericson M, Ho C, Matheson GO. Asymptomatic tibial stress reactions: MRI detection and clinical follow-up in distance runners. AJR Am J Roentgenol 2004;183(3):635-8.

4. Collier R. Low-tech running shoes in high demand. CMAJ 2011;183(1):E20.

5. De Wit B, De Clercq D, Aerts P. Biomechanical analysis of the stance phase during barefoot and shod running. Journal of Biomechanics 2000;33(3):269-78.

6. Deutsch AL, Coel MN, Mink JH. Imaging of stress injuries to bone. Radiography, scintigraphy, and MR imaging. Clin Sports Med 1997;16(2):275-90.

7. Divert C, Mornieux G, Baur H, Mayer F, Belli A. Mechanical comparison of barefoot and shod running. Int J Sports Med 2005;26(7):593-8.

8. Giuliani J, Masini B, Alitz C, Owens BD. Barefoot-simulating footwear associated with metatarsal stress injury in 2 runners. Orthopedics 2011;34(7):e320-3.

9. Jones BH, Thacker SB, Gilchrist J, Kimsey CD, Jr., Sosin DM. Prevention of lower extremity stress fractures in athletes and soldiers: a systematic review. Epidemiol Rev 2002;24(2):228-47.

10. Kiuru MJ, Niva M, Reponen A, Pihlajamaki HK. Bone stress injuries in asymptomatic elite recruits: a clinical and magnetic resonance imaging study. Am J Sports Med 2005;33(2):272-6.

11. Kiuru MJ, Pihlajamaki HK, Hietanen HJ, Ahovuo JA. MR imaging, bone scintigraphy, and radiography in bone stress injuries of the pelvis and the lower extremity. Acta Radiol 2002;43(2):207-12.

12. Lazzarini KM, Troiano RN, Smith RC. Can running cause the appearance of marrow edema on MR images of the foot and ankle? Radiology 1997;202(2):540-2.

13. Lieberman DE, Venkadesan M, Werbel WA, Daoud AI, D'Andrea S, Davis IS, Mang'eni RO, Pitsiladis Y. Foot strike patterns and collision forces in habitually barefoot versus shod runners. Nature 2010;463(7280):531-5.

14. Macintyre JG, Taunton JE, Clement DB, Lloyd-Smith DR, McKenzie DC, Morrell RW. Running Injuries: A Clinical Study of 4,173 Cases. Clinical Journal of Sports Medicine 1991;1(2):81-7. 
15. Matheson GO, Clement DB, McKenzie DC, Taunton JE, Lloyd-Smith DR, MacIntyre JG. Stress fractures in athletes. A study of 320 cases. Am J Sports Med 1987;15(1):46-58. 16. Niva MH, Sormaala MJ, Kiuru MJ, Haataja R, Ahovuo JA, Pihlajamaki HK. Bone stress injuries of the ankle and foot: an 86-month magnetic resonance imaging-based study of physically active young adults. Am J Sports Med 2007;35(4):643-9.

17. Rixe JA, Gallo RA, Silvis ML. The barefoot debate: can minimalist shoes reduce runningrelated injuries? Curr Sports Med Rep 2012;11(3):160-5.

18. Robbins SE, Hanna AM. Running-related injury prevention through barefoot adaptations. Med Sci Sports Exerc 1987;19(2):148-56.

19. Spitz DJ, Newberg AH. Imaging of stress fractures in the athlete. Radiol Clin North Am 2002;40(2):313-31.

20. Squadrone R, Gallozzi C. Biomechanical and physiological comparison of barefoot and two shod conditions in experienced barefoot runners. J Sports Med Phys Fitness 2009;49(1):6- 13.

21. Trappeniers L, De Maeseneer M, De Ridder F, Machiels F, Shahabpour M, Tebache C, Verhellen R, Osteaux M. Can bone marrow edema be seen on STIR images of the ankle and foot after 1 week of running? Eur J Radiol 2003;47(1):25-8.

22. Vibram. http://www.vibramfivefingers.com. [web page] [cited 2010 January].

23. Warburton M. Barefoot Running. Sportscience. [Review]. 2001;5(3).

24. Wentz L, Liu PY, Haymes E, Ilich JZ. Females have a greater incidence of stress fractures than males in both military and athletic populations: a systemic review. Mil Med 2011;176(4):420-30. 